\title{
Production and characterization of a monoclonal antibody against an Ascaris suum allergenic component
}

R.R. Pires, T.M. O shiro, D.M. Itami, I. Fernandes and M.F. Macedo-Soares
Laboratório de Immunopatologia, Instituto Butantan, São Paulo, SP, Brasil

\section{Correspondence \\ M.F. Macedo-Soares \\ Laboratório de Imunopatologia \\ Instituto Butantan \\ Av. Vital Brasil, 1500 \\ 05503-900 São Paulo, SP \\ Brasil \\ E-mail: fmacedo@ usp.br}

Presented at the XVI Annual Meeting of the Federação de Sociedades de Biologia Experimental, Caxambu, MG, Brazil, August 22-25, 2001.

R.R. Pires, T.M. O shiro and D.M. Itami are recipients of FAPESP fellowships.

Received April 12, 2001 Accepted June 12, 2001

\section{Abstract}

Ascaris suum allergenic components (PIII) separated by gel filtration chromatography of an adult worm extract were used to immunize $\mathrm{BALB} / \mathrm{c}$ mice. Popliteal lymph node cells taken from the immunized animals were fused with SP2/O myeloma cells using polyethylene glycol (MW 1450) as fusogen. The hybridomas were cultured in HATcontaining medium and cloned at limiting dilutions. Supernatants from the growing hybrids were screened by ELISA using plates coated with PIII or the A. suum crude extract. The monoclonal antibody obtained, named MAC-3 (mouse anti- $A$. suum allergenic component), is an IgG1 kappa mouse immunoglobulin that specifically recognizes a 29,000 molecular weight protein (called allergenic protein) with an affinity constant of $1.7 \times 10^{9} \mathrm{M}^{-1}$. The A. suum components recognized by MAC-3 induce specific IgE antibody production in immunized $\mathrm{BALB} / \mathrm{c}$ mice. Ascitic fluid induced in Swiss mice by injecting ip the hybridoma cells and incomplete Freund's adjuvant was purified by affinity chromatography using a protein A-Sepharose column. The purified monoclonal antibody was then coupled to activated Sepharose beads in order to isolate the $A$. suum allergenic component from the whole extract by affinity chromatography.

Helminth infections are associated with production of substantial amounts of both parasite-specific and nonspecific IgE, occurrence of immediate hypersensitivity reactions and proliferation of hypersensitivityassociated cells, such as mast cells and eosinophils. The ascaroid nematodes are particularly active in inducing atopic reactions $(1,2)$. Regarding Ascaris suum, extracts in various stages of purification have been widely used for allergen characterization in different animal species (3-5). Several allergens have been isolated from worm extracts, body fluid or culture supernatant. A potent allergen was identified in the body fluid of adult $\mathrm{A}$. suum and characterized as a 14,000 molecular weight protein that induces an $\operatorname{IgE}$ antibody response in a rat model (6). It was also demonstrated that $A$. suum potentiates the IgE response in different species, although attempts made using the mouse model were unsuccessful (7). Working with $A$. suum, we have previously shown that whole extract obtained from adult worms suppresses the production of antibodies to an unrelated antigen in the mouse system (8). Moreover, we 
have demonstrated that the suppressive components present in the A. suum extract could be isolated from a 29,000 molecular weight component which induces high levels of $\operatorname{IgE}$ antibody (9). In order to further characterize this allergenic component, the aim of the present study was to produce a specific monoclonal antibody $(\mathrm{mAb})$ which provides an important tool for a better identification of the allergen.

$\mathrm{BALB} / \mathrm{c}$ mice weighing 18-22 $\mathrm{g}$ (provided by the animal house of Butantan Institute) were injected into the footpad with an emulsion of complete Freund's adjuvant containing $40 \mu \mathrm{g}$ of $A$. suum allergenic component purified as previously described (8). Two weeks later, the animals received $40 \mu \mathrm{g}$ of the antigen in incomplete Freund's adjuvant by the same route and the popliteal lymph nodes were excised 3 days later for fusion with a nonsecreting SP2/O cell line using $50 \%$ polyethylene glycol (MW 1450). The hybridomas were cultured in HAT (hypo-

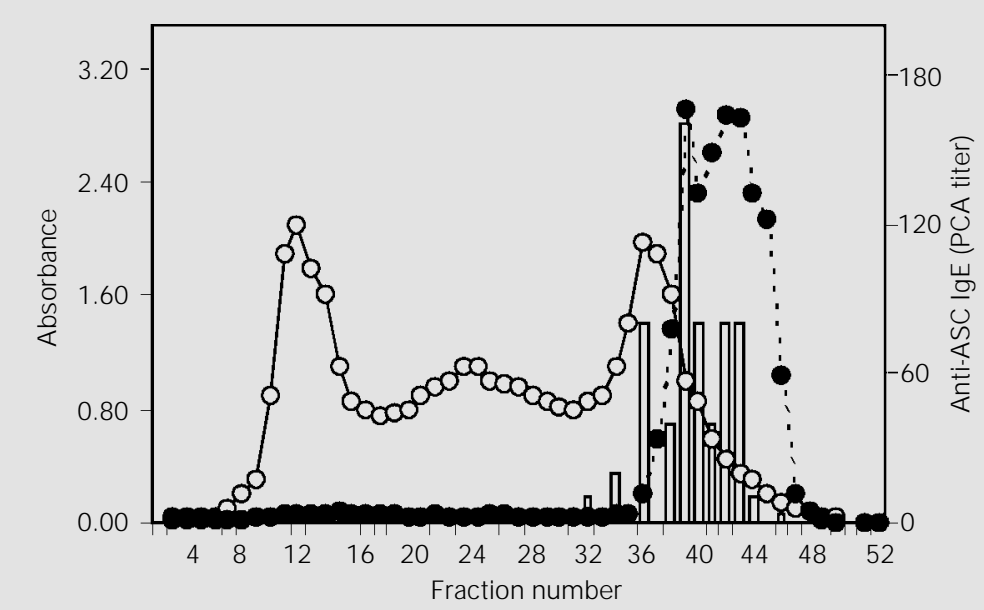

Figure 1. Specificity of mouse anti-Ascaris suum component (MAC-3) monoclonal antibodies. The open circles represent the gel filtration profile of A. suum crude (ASC) extract (peak I, fractions 11 to 16; peak II, fractions 26 to 31; peak III, fractions 37 to 50). Thirty milligrams of ASC was applied to a Sephacryl S-300 column and fractions of $2.0 \mathrm{ml}$ were collected with PBS, pH 7.2. Absorbance was determined at $280 \mathrm{~nm}$. Each fraction was injected with alumn adjuvant into BALB/C mice in order to evaluate the IgE antibody production. The bars represent the passive cutaneous anaphylaxis (PCA) titer of mouse sera three weeks after immunization. The specificity of MAC-3 was determined by ELISA using polystyrene plates absorbed with each fraction and incubated with MAC-3 plus a peroxidase-labeled rat monoclonal antibody against mouse IgG1. The filled circles represent the absorbance obtained at $492 \mathrm{~nm}$. xanthine-aminopterin-thymidine)-containing medium and cloned under limiting dilution conditions. Supernatants from growing hybrids were screened by ELISA using plates coated with $A$. suum allergenic components purified by gel filtration (PIII) and visualized with $0.1 \mu \mathrm{g}$ of peroxidase-labeled rat $\mathrm{mAb}$ against different mouse Ig isotypes (kindly provided by Dr. H. Bazin, Experimental Immunology Unit, University of Louvain, Brussels, Belgium).

The cloned hybrid cells produced an IgG1 kappa mAb named MAC-3 - mouse anti- $A$. suum allergenic component. The specificity of MAC-3 mAb was determined by ELISA using plates coated with each fraction eluted from a Sephacryl S-300 column to which 30 $\mathrm{mg}$ of $A$. suum extract was applied. At each step, the plates were incubated for $1 \mathrm{~h}$ at $37^{\circ} \mathrm{C}$ and washed five times with PBS, $\mathrm{pH}$ 7.2. They were then saturated with $5 \%$ defatted milk in PBS and $1 \mu \mathrm{g} /$ well of MAC-3 was added followed by peroxidase-labeled rat anti-mouse IgG1 mAb and $100 \mu 1 /$ well of $o$ phenylenediamine diluted in sodium citrate buffer, $\mathrm{pH} 5.0$, at a concentration of $0.4 \mathrm{mg} /$ $\mathrm{ml}$. The $\mathrm{mAb}$ was visualized by the addition of $0.012 \% \mathrm{H}_{2} \mathrm{O}_{2}$. Plates were read in a Titerteck Multiskan apparatus at $492 \mathrm{~nm}$. The MAC-3 mAb recognized only fractions eluted in the third peak (fractions 37 to 50), represented by the low molecular weight proteins of the A. suum extract (Figure 1).

The allergenic properties of $A$. suum components were determined by their ability to induce IgE measured by passive cutaneous anaphylaxis (PCA) in rats according to the method of Mota and Wong (10). Several dilutions of the serum from mice immunized with $\mathrm{Al}(\mathrm{OH})_{3}(7.5 \mathrm{mg})$ plus $250 \mu \mathrm{l}$ of each fraction of $A$. suum crude extract eluted on a Sephacryl S-300 column were injected intradermally into the shaved back of three rats. The animals were challenged intravenously with $0.5 \mathrm{mg}$ of $A$. suum crude extract in $0.25 \%$ Evans blue solution after a sensitization period of 18-24 h. The PCA titer was 
expressed as the reciprocal of the highest dilution that produced a lesion of more than $5 \mathrm{~mm}$ in diameter. The results shown in Figure 1 demonstrate that the same fractions recognized by MAC-3 induced specific IgE antibody production.

A large amount of MAC-3 was purified from ascitic fluid of Swiss mice injected with the secreting hybridoma and incomplete Freund's adjuvant by affinity chromatography using a protein A-Sepharose column. Purified MAC-3 was conjugated with activated Sepharose and the adult worm crude extract was applied to the column. The allergenic protein was then eluted using citrate buffer, $\mathrm{pH} 2.8$. Allergenic protein purity was evaluated by SDS-PAGE and by immunoblotting. The protein banding pattern of the whole extract was quite complex, as revealed by SDS-PAGE performed on a $7.5 \%$ acrylamide gel at $20-\mathrm{mA}$ constant current and visualized with silver staining (Figure 2). On the other hand, the material eluted from the MAC-3-Sepharose column (allergenic protein) showed a single band corresponding to a 29,000 molecular weight protein. The different components of the whole extract separated by SDS-PAGE were transferred to a nitrocellulose membrane that was then treated with MAC-3, followed by the addition of anti-mouse IgG1 mAb labeled with peroxidase plus $\mathrm{H}_{2} \mathrm{O}_{2}$ and 4-chloro-1-naphthol. As shown in Figure 2, the mAb MAC-3 recognized only the 29,000 molecular weight protein present in the whole extract.

MAC-3 mAb binds to allergenic protein with an affinity constant of $1.7 \times 10^{9} \mathrm{M}^{-1}$, as

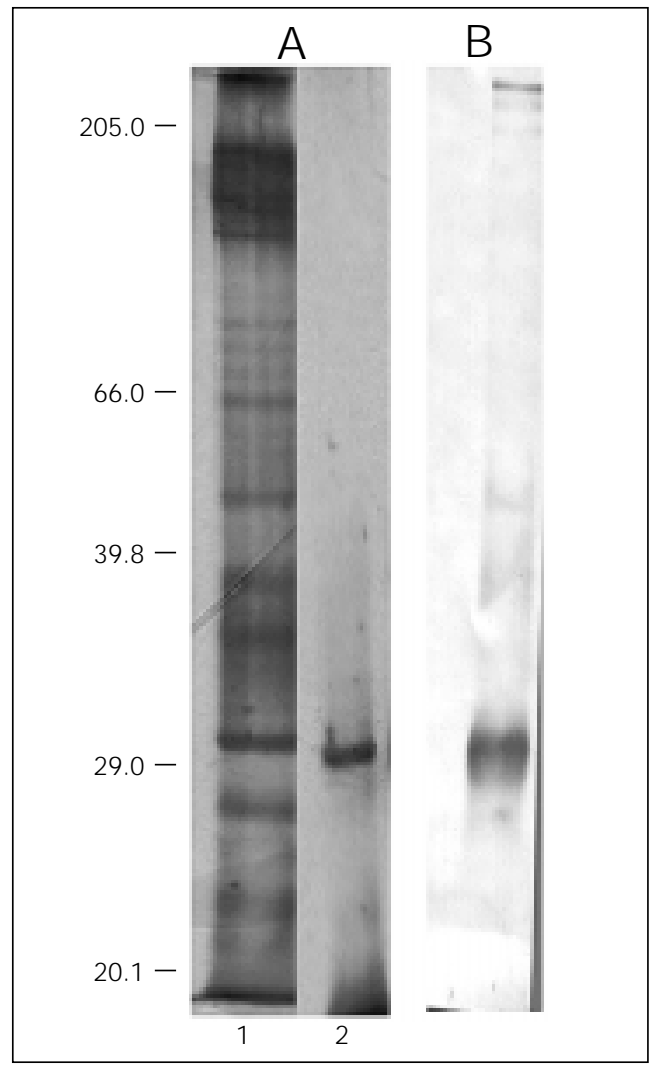

Figure 2. SDS-PAGE patterns (A) of whole extract (lane 1) or the allergenic protein from Ascaris suum recognized by $\mathrm{MAC}-3$ monoclonal antibody (lane 2). The molecular weight markers are represented at the left. $B$, Immunoblotting of $A$. suum components using MAC-3 plus a peroxidase-labeled rat monoclonal antibody against mouse IgG1. determined by ELISA according to Van Heymingen et al. (11).

We produced a mouse $\mathrm{mAb}$ against the A. suum allergen that is an IgG1 kappa immunoglobulin with an affinity constant of $1.7 \times 10^{9} \mathrm{M}^{-1}$ and which recognizes specifically a 29,000 molecular weight protein from the adult worm extract. This mAb will be used for the identification of allergenic protein in different stages of the A. suum life cycle as compared to immunosuppressive components.

\section{References}

1. J arret EE \& Miller HRP (1982). Production and activities of IgE in helminth infection. Progress in Allergy, 31: 178-233.

2. Barriga OO (1984). Immunomodulation by nematodes: A review. Veterinary Parasitology, 14: 299-320.

3. Weizger I, Patterson R \& Pruzanski JD (1968). Ascaris hypersensitivity in the rhesus monkey. I. A model for the study of immediate type hypersensitivity in the primate. J ournal of Allergy, 91: 14-22.

4. Bradbury SM, Percy DH \& Strejan GH (1974). Immunology of Ascaris suum infection. I. Production of reaginic antibodies to worm components in rats. International Archives of Allergy and Applied Im- munology, 46: 498-511.

5. Stromberg BE (1980). Potentiation of the reaginic (IgE) antibody response to ovalbumin in the guinea pig with a soluble metabolic product from Ascaris suum. J ournal of Immunology, 125: 833-836.

6. McGibbon AM, Christie J F, Kennedy MW \& Lee TD (1990). Identification of the ma- 
jor ascaris allergen and its purification to homogeneity by high-performance liquid chromatography. Molecular and Biochemical Parasitology, 39: 163-171.

7. Crandall CA (1976). Ascaris suum: homocytotropic antibody responses in mice. Experimental Parasitology, 39: 69-73.

8. Soares MFM, Macedo MS \& Mota I (1987). Suppressive effect of an Ascaris suum extract on IgE and IgG antibody responses in mice. Brazilian J ournal of Medical and Biological Research, 20: 203211.

9. Macedo-Soares MF, Mota I \& Macedo MS (1992). Isolation of Ascaris suum components which suppress IgE antibody responses. International Archives of Allergy and Applied Immunology, 97: 37-43.
10. Mota I \& Wong D (1969). Homologous passive cutaneous anaphylactic activity of mouse antisera during the course of immunization. Life Sciences, 8: 813-820.

11. Van Heymingen V, Brock DJ \& Van Heymingen S (1983). A simple method for ranking the affinities of monoclonal antibodies. J ournal of Immunological Methods, 62: 147-153. 